\title{
Long term evolution of a dam reservoir subjected to regular flushing events
}

\author{
L. Guertault ${ }^{1}$, B. Camenen ${ }^{1}$, C. Peteuil ${ }^{2}$, and A. Paquier ${ }^{1}$ \\ ${ }^{1}$ Irstea, UR HHLY, centre de Lyon-Villeurbanne, 5 rue de la Doua, CS 70077, 69626 Villeurbanne cedex, France \\ ${ }^{2}$ Compagnie Nationale du Rhône, 2 rue André Bonin, 69316 Lyon Cedex 04, France
}

Correspondence to: L. Guertault (lucie.guertault@irstea.fr)

Received: 11 October 2013 - Revised: 20 January 2014 - Accepted: 27 January 2014 - Published: 1 April 2014

\begin{abstract}
An analysis of the long term morphological evolution of the Génissiat reservoir (France) is provided. First, a methodology for bathymetric data processing and reservoir sediment volume budget calculation is described. An estimation of global uncertainties in volume calculation is proposed. The reservoir bathymetric budget for several dam flushing events and interflush periods is presented, showing the global decrease of deposited sediment volume with time. The spatial dynamics of the reservoir subreaches is highlighted and typical patterns in flush and interflush periods are identified.
\end{abstract}

\section{Introduction}

Reservoirs formed by dams on natural Rivers can alter the balance between sediment inflow and outflow (Morris and Fan, 1998). Because of their low flow velocities, they trap a significant quantity of incoming sediment introducing downstream filling. Sediment issues do not only affect the reservoirs through water storage loss but can also influence downstream patterns creating bed degradation, accelerating bank failure and scour formation. Among the several technical solutions for reservoir desiltation, a common one used by dam operators is flushing. Reservoir flushing consists of lowering the water level so that the inflowing water is routed through the reservoir with a hydraulic regime similar to the natural Riverine condition (Brandt, 2000). Higher velocities and bed shear stresses increase the sediment transport capacity and allow to erode part of the material deposited in the reservoir (Di Silvio, 2001).

The Rhône River is one of the major European Rivers. It flows from the Swiss Alps through Switzerland and France to the Mediterranean sea. The reach from the Swiss border to Lyon is known as the French Upper Rhône River (Fig.1). Output water from Lake Geneva is clear water with a controlled discharge. Two kilometers downstream is the confluence with the Arve River, which is the main tributary of the Upper Rhône River, providing almost all the sediment load, which is estimated between 1 and 3 million tons per year. Two dams are built on the Swiss Rhône River: Verbois and Chancy Pougny dams. They trap a large quantity of sediment from the Arve River. Downstream the $70 \mathrm{~m}$ high Génissiat dam and four additional run-of-River developments operated by Compagnie Nationale du Rhône (CNR) exist.

Génissiat dam has been in operation since 1948. The reservoir is $23 \mathrm{~km}$ long with an initial volume of 56 million $\mathrm{m}^{3}$. Nowadays it is filled with approximately 14 million $\mathrm{m}^{3}$ of sediment. In the upper part of the reservoir, one can find a large valley (the Etournel site) with a secondary channel and several islands. Then the River enters in a canyon where the flow is confined and under the dam hydraulic influence. Close to the dam, the water height is about $60 \mathrm{~m}$. Granulometric surveys (Bouchard and Dumond, 2000; Lerch and Thizy, 2013) show a typical downstream fining in the reservoir channel: gravel and coarse sand in the upper part of the reservoir to a predominance of silt in the last $10 \mathrm{~km}$ of the reservoir. A transversal grain sorting is also highlighted, as banks materials are finer than the channel ones. These conditions lead us to consider that both bedload for coarse sediments and suspended load for fine sediments are involved in the reservoir dynamics.

\section{Flushing operations on the Upper Rhône River}

Since the early 20th century, regular flushes have been conducted on the Upper Rhône River to prevent flood hazards 


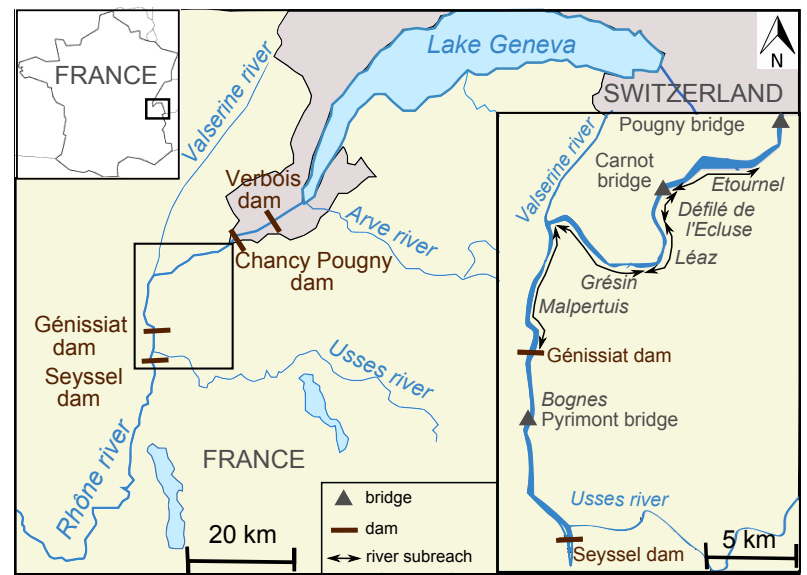

Fig. 1. Location of the study site.

in the lowest parts of Geneva city due to the bed aggradation of the Verbois reservoir. A large quantity of sediment is removed from the Verbois reservoir during a flush and supporting operations are carried out through the French Upper Rhône River, particularly to prevent large deposition in the Génissiat reservoir. Since 1981, the CNR conducts environmental friendly flushing to release suspended sediment concentrations tolerable by the fluvial environment downstream of the Génissiat dam (Peteuil et al., 2013). In Fig. 2, the evolution of the longitudinal profile of the Génissiat reservoir is presented for the last $60 \mathrm{yr}$.

- From 1955 to 1975, seven Swiss-French flushing operations were carried out. Swiss and French reservoirs were flushed and then risen together. At the Génissiat dam, water was mainly evacuated through the dam by the half depth gate and the surface spillway. A stable profile is observed in the upper $10 \mathrm{~km}$ of the reservoir while large deposition ( $20 \mathrm{~m}$ in $20 \mathrm{yr}$ ) occurred further downstream of the Génissiat reservoir. The bathymetric evolution was related to a reservoir management that did not promote sediment release downstream of the Génissiat dam. As a consequence, the annual mean deposition rate was about $50010^{3} \mathrm{~m}^{3}$;

- From 1975 to 1997, six flushing operations were carried out. The reservoir water level was lowered by about $10 \mathrm{~m}$ and then risen together with Swiss reservoirs. Water was also briefly evacuated through the dam bottom gate, promoting sediment release downstream of the dam. The mean deposition rate has decreased and the main morphological changes occurred in the last $5 \mathrm{~km}$;

- From 1997 to 2012, four flushing operations were carried out. The longitudinal profile was in a quasi equilibrium. Since 1997, flushing operations have been carried out following a specific procedure: first lowering

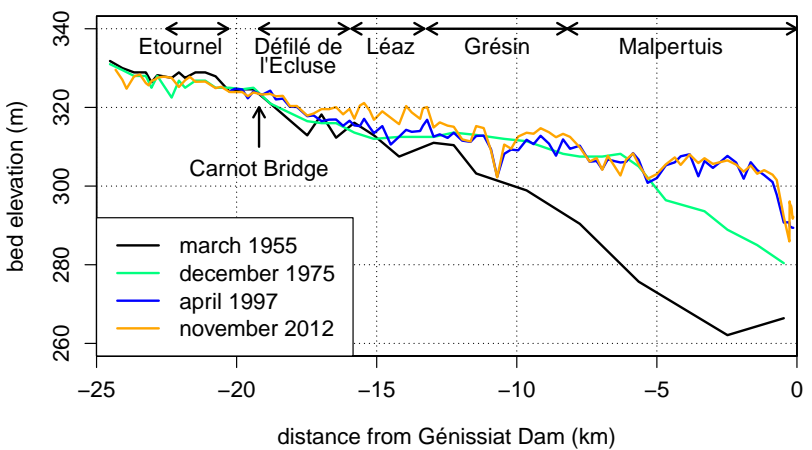

Fig. 2. Evolution of the Longitudinal profile of the Génissiat reservoir.

the Génissiat reservoir water level by about $20 \mathrm{~m}$ during the first week of the flush, and then rising it by $10 \mathrm{~m}$ during the second week dedicated to Swiss dam flushes. The dam bottom gate is opened during almost all the time to empty the reservoir. Indeed, this gate opening allows to release downstream a higher concentration due to the vertical gradient in the concentration profile observed in the reservoir and reduces the reservoir filling.

The objective of the paper is to highlight the spatial dynamics of the Génissiat reservoir for flushing events and interflush periods to better understand the hydro-sedimentary processes involved in its morphological evolution since 1984. A methodology to calculate those budgets is proposed. Uncertainty sources are listed to estimate global uncertainty.

\section{Methodology for volume calculation and uncertainties estimation}

Bathymetric surveys using a mono beam echo sounder coupled to a DGPS are carried out by CNR before and after flushing events. Since 1984, data are sufficiently accurate and homogeneous to allow volume calculation using bathymetric difference. About 110 transversal profiles with an average number of points per section from 15 to 45 and with distances ranging from 20 to $500 \mathrm{~m}$ are measured.

\subsection{Bathymetric data post processing}

A first step consists in completing all the profiles with points based on topographic data or other profiles measured at the same section assuming the banks have not moved. The next step is to define the same boundaries for each measured profile at a given cross section to use the same projection axis to convert XYZ data into abscissa-elevation coordinate. Then the distance between two consecutive sections $L_{i}$ can be estimated using GIS Tools. This distance is defined as the length of the curvilinear arc joining the middle of two consecutive sections (Fig. 3). 


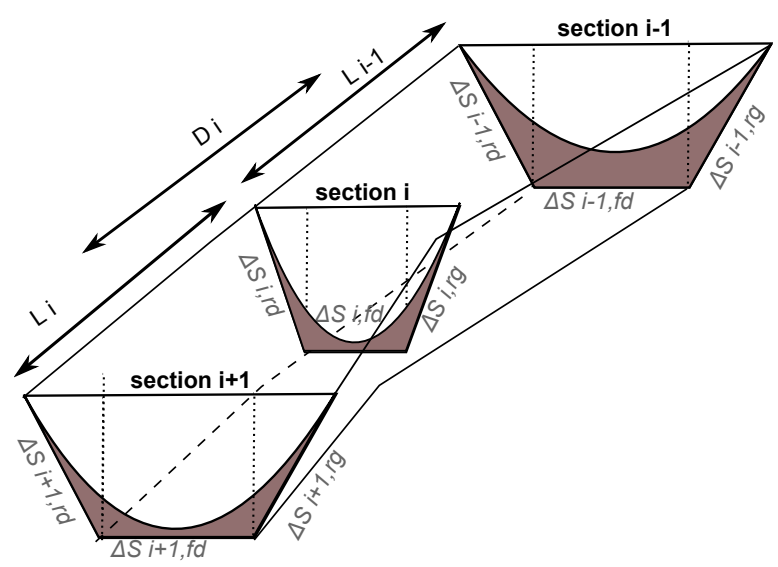

Fig. 3. Representation of the calculation variables $\Delta S_{i, \mathrm{bk}}=$ $\Delta S_{i, \text { left }}+\Delta S_{i, \text { right }}$

\subsection{Volume calculation}

The volume calculation is based on bathymetric data differences between two dates $t_{1}$ and $t_{2}$. The main variables used are defined in Fig. 3. The overall volume budget $V$ in the reservoir is the sum of all the intermediate volumes $V_{i}$ associated to geometrical variations of the cross section $i$ between $t_{1}$ and $t_{2}$.

$V=\sum_{i=1}^{M} V_{i}=\sum_{i=1}^{M} D_{i} \Delta S_{i}$

where $\Delta S_{i}$ is the area evolution of section $i$ between $t_{1}$ and $t_{2}$ defined as the difference between profile areas calculated at $t_{1}$ and $t_{2}$ and approximated using a trapezoidal description. $D_{i}$ is the application length defined as the sum of the two half distances between consecutive sections and $M$ is the number of cross sections.

\subsection{Uncertainty estimation}

There are two contributions to uncertainty: imprecision $u_{\mathrm{P}}$ and bias $u_{\mathrm{B}}$. Imprecision is related to measuring instrument sensitivity and calculation methods. Bias is related to the discrete description of bathymetric data and to the fact that a given cross section cannot be representative of the bed evolution around its location.

The two uncertainty sources (bias and imprecision) are assumed independent. The total uncertainty $u(V)$ is written:

$u(V)=\sqrt{\sum_{i=1}^{M} u_{\mathrm{P}}^{2}\left(V_{i}\right)+u_{\mathrm{B}}^{2}\left(V_{i}\right)}$

\subsubsection{Imprecision}

Imprecision $u_{\mathrm{P}}\left(V_{i}\right)$ in the volume related to the section $i$ is caused by imprecision on the area $u_{\mathrm{P}}\left(\Delta S_{i}\right)$ and imprecision in the application length $u_{\mathrm{P}}\left(D_{i}\right)$.

$u_{\mathrm{P}}\left(V_{i}\right)=V_{i} \sqrt{\left[\frac{u_{\mathrm{P}}\left(S_{i}\right)}{S_{i}}\right]^{2}+\left[\frac{u_{\mathrm{P}}\left(D_{i}\right)}{D_{i}}\right]^{2}}$

We estimate that the precision of the GIS measuring tool is $\pm 5 \mathrm{~m}$, so that the standard individual uncertainty is $u_{\mathrm{P}}\left(D_{i}\right)=$ $5 / \sqrt{3}=2.9 \mathrm{~m}$, according to the GUM (Joint Committee For Guides in Metrology, 2008).

Imprecision $u_{\mathrm{P}}\left(\Delta S_{i}\right)$ in the area is caused by imprecisions in measurement and calculation methodology. The different steps of the methodology, more particularly cross sectional axis projection, allow to reduce imprecision and are neglected compared to measurement imprecision. Considering the instruments used and measured parameters, the relative imprecision of the $\mathrm{XY}$ coordinates is neglected compared to the relative imprecision on height. We estimate that the average precision of the sounder is $\pm 5 \mathrm{~cm}$. The individual standard imprecision uncertainty of the height for a point is $u_{\mathrm{P}}(z)=0.05 / \sqrt{3}=0.029 \mathrm{~m}$.

$u_{\mathrm{P}}\left(\Delta S_{i, t}\right)=u_{\mathrm{P}}(z) \sqrt{\left[\sum_{t=\left[t_{1}, t_{2}\right]} \sum_{k=1}^{N(t)-1}\left(x_{k+1, t}-x_{k, t}\right)^{2}\right]}$

\subsubsection{Bias}

Bias of the volume related to the section $i u_{\mathrm{B}}\left(V_{i}\right)$ is due to the lack of information between cross sections. When the geometrical evolution is very different between consecutive sections, the hypothesis of a constant evolution of $\Delta S_{i}$ can be questioned. Moreover, banks are subjected to local phenomena such as bank failure which cannot be always captured. Consequently we suggest the following formula for this uncertainty:

$u_{\mathrm{B}}\left(V_{i}, l\right)=\alpha_{i, l}\left[\left(\left|S_{i, l}-S_{i-1, l}\right|\right) L_{i-1}+\left(\left|S_{i+1, l}-S_{i, l}\right|\right) L_{i}\right]$

where $l=[\mathrm{bk}, \mathrm{mc}]$ for bank and main channel and $\alpha_{(i, l)}$ is a coefficient function of the position in space. As the slope is a significant parameter driving morphological evolutions: $\alpha_{i, m c}=\left(\left|p_{i, t_{1}}\right|+\left|p_{i, t_{2}}\right|\right) / 2$, where $p_{i, t_{1}}$ and $p_{i, t_{2}}$ are respectively local slopes based on the thalweg elevation at the section $i$ at times $t_{1}$ and $t_{2} . \alpha_{\mathrm{mc}}$ varies from 0.001 to 0.25 .

For banks, the equilibrium slope of the reservoir sediments is used, calculated using the stability angle $\phi$ for silt and clay, $\alpha_{i, \mathrm{bk}}=\tan \phi=0.14$.

As volumes related to banks and channel are assumed independent, the bias uncertainty of the whole section is:

$u_{\mathrm{B}}\left(V_{i}\right)=\sqrt{\sum_{l=[\mathrm{mc}, \mathrm{bk}]} u_{\mathrm{B}}^{2}\left(V_{i, l}\right)}$

\section{Bathymetric balance of the Génissiat reservoir}

The methodology is applied to estimate volume budgets of the reservoir since 1984. Standard uncertainties are 
Table 1. Sediment volume budget from 1984 to 2012 (Positive values correspond to deposited volumes and negative ones correspond to eroded volumes. The volume budget includes dredged volumes. $Q_{\mathrm{F}}$ is the annual maximum daily River discharge. $Q_{\mathrm{F}, \text { Rhône }}=$ $800 \mathrm{~m}^{3} \mathrm{~s}^{-1}, Q_{\mathrm{F}, \text { Arve }}=300 \mathrm{~m}^{3} \mathrm{~s}^{-1}$ )

\begin{tabular}{|c|c|c|c|c|}
\hline \multirow{2}{*}{ Period } & \multicolumn{2}{|c|}{$\begin{array}{l}\text { Volumes } \\
\left(10^{3} \mathrm{~m}^{3}\right)\end{array}$} & \multicolumn{2}{|c|}{$\begin{array}{c}\text { Duration with } Q>Q_{\mathrm{F}} \\
\text { (days) }\end{array}$} \\
\hline & budget & dredgings & $\begin{array}{r}\text { Rhône } \\
\text { (Pougny) }\end{array}$ & $\begin{array}{r}\text { Arve } \\
\text { (Geneva) }\end{array}$ \\
\hline 1984 Flush & $855 \pm 79$ & & & \\
\hline 1984-1987 & $1513 \pm 101$ & -15 & 0 & 4 \\
\hline 1987 Flush & $673 \pm 72$ & & & \\
\hline 1987-1990 & $293 \pm 72$ & & 10 & 11 \\
\hline 1990 Flush & $431 \pm 48$ & & & \\
\hline 1990-1993 & $740 \pm 85$ & -388 & 2 & 12 \\
\hline 1993 Flush & $795 \pm 66$ & & & \\
\hline 1993-1997 & $-137 \pm 54$ & -8 & 5 & 5 \\
\hline 1997 Flush & $374 \pm 81$ & & & \\
\hline $1997-2000$ & $151 \pm 121$ & -120 & 5 & 3 \\
\hline 2000 Flush & $672 \pm 126$ & & & \\
\hline $2000-2003$ & $6 \pm 115$ & & 8 & 3 \\
\hline 2003 Flush & $-357 \pm 115$ & & & \\
\hline 2003-2012 & $408 \pm 135$ & -139 & 9 & 7 \\
\hline 2012 Flush & $1472 \pm 60$ & & & \\
\hline
\end{tabular}

calculated with the methodology and multiplied by a coverage factor $k=2$ to quantify them with a confident interval at $95 \%$ (Joint Committee For Guides in Metrology, 2008).

\subsection{Sediment volume budget from 1984 to 2012}

The volume budget of the reservoir is presented in Table 1 . Uncertainties vary between 50 and $13510^{3} \mathrm{~m}^{3}$. On average, bias represents $70 \%$ of the uncertainty on the total budget. Nevertheless, it yields most of the variability in the uncertainty. Indeed, bias and so uncertainty are higher when the number of cross sections is low and when the morphological evolution is not uniform along the reservoir.

- From 1984 to 2012, the global balance for flushing operations is positive. Those events last approximately two weeks but contribute to half the volume budget of the reservoir. Nevertheless, a high variability in the Génissiat reservoir flushing events budget can be observed, with a negative budget in 2003 and a significant positive budget in 2012. This can be attributed to the variability in both sediment input and reservoir management conditions;

- In general, the volume budget is positive during interflush periods. The negative budget for the 1993-1997 interflush period is not entirely representative because bathymetric data was not surveyed for the upper four kilometers of the reservoir before the 1997 flush (and so for the 1997 flush). The deposited volume depends on water and solid inflows natural variability during in-

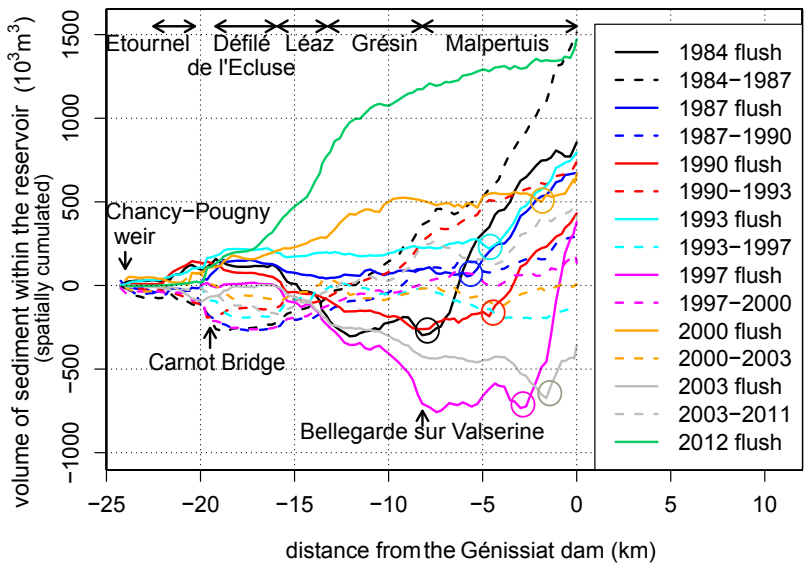

Fig. 4. Spatially cumulated sediment volume budget of the Génissiat reservoir since 1984 (circles represent sharp changes in sediment dynamics during flushes).

terflush periods. Since 1991, dredging operations have been carried out in the reservoir, particularly close to the dam and part of the bed material deposited there is thus removed. Moreover, from 1970 to 1995 , mechanical extractions of gravel where operated in the Etournel site. The total volume extracted is estimated to 500 $10^{3} \mathrm{~m}^{3}$.

\subsection{Spatial dynamics of the reservoir and effects of flushes from 1984 to 2012}

This analysis allows a detailed description of the spatial dynamics of deposition and erosion in the reservoir for both interflush periods and flushing events. Figure 4 shows the spatially cumulated volume budget of the reservoir calculated from Pougny as a function of the streamwise location for different flushes and interflush periods since 1984. The Génissiat dam is located at the abscissa 0 and the plotted value at this location corresponds to the total volume deposited or eroded in the reservoir.

Homogeneous subreaches of the River can be defined:

- In the Etournel natural site the reservoir dynamics are the opposite during flush and interflush periods, showing respectively deposition and erosion. This behaviour explains the stability of the longitudinal profile in this reach;

- Downstream of the Carnot Bridge, the reach named Défilé de l'Écluse is in an equilibrium state, may be because of the narrow but homogeneous section;

- In Léaz and Grésin Gorges, deposition occurs during interflush periods and variable evolutions occur during flushes. For the 2003 flush, these subreaches show a negative volume budget, while a significant deposition occured during the 2012 flush; 
(a)

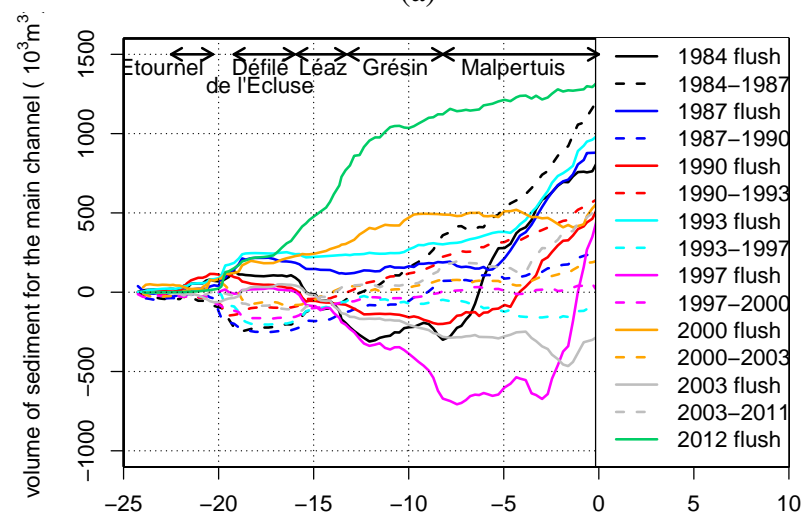

(b)

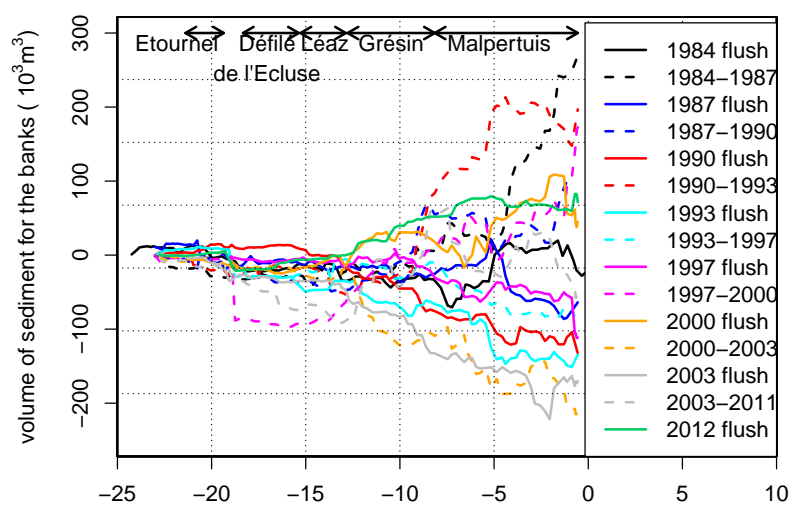

Fig. 5. Spatially cumulated sediment volume budget in Génissiat reservoir since 1984 separating main channel (a) and banks (b).

- In the Malpertuis reach, since it corresponds to the immediate upstream reach of the dam, deposition is the global trend in the reach dynamics during both flushing events and interflush periods. During flushes, intense deposition is generally observed. This deposition could result from the second phase of the flushing operation, when the rise of the reservoir water level leads to the deposition of the sediments coming from Swiss reservoirs. During interflush period, there is also significant deposition since velocities are very low.

The methodology allows to split the total budget into bank and channel budgets (Fig. 5).

- The main channel contribution is about $80 \%$ of the global budget and prevails to the overall reservoir dynamics.

- In the upper subreaches of the reservoir, the contribution of the banks in the volume budget is negligible, except in the case of a local significant bank failure (interflush 1997-2000, $20 \mathrm{~km}$ upstream of the dam). In Grésin gorges (13.5 km upstream of the dam), the contribution of banks increases.
- Continuous sedimentation of silt and clay causes floodplain and banks deposits while the main channel shape is maintained by repeated flushing operations. During flushes, banks are alternately exposed and submerged, accelerating bank failure rate. Typically, flushing operations lead to bank erosion and interflush periods to bank aggradation.

\section{Discussion}

\subsection{Bedload and suspended load transport}

At present, the sediment input at the upper part of the reservoir is poorly known. It depends on upstream Swiss reservoir release for fine sediments and on the contribution of the reach downstream Chancy-Pougny dam for coarser sediments. An erosion-deposition system is observed in the upstream gravel-bed reach indicating a dynamics dominated by bedload transport. This has been confirmed by a hydrophone positioned at Pougny (Geay , 2013) that has shown that bedload occurs in this upper reach even for relatively low flows. Since bed material extractions have been forbidden, the Etournel site tends to aggrade with the creation of larger islands and some clogging in the secondary channels.

In the lower reaches, sediment transport processes are highly dependant of the reservoir water level. For high water levels, corresponding to interflush periods, flow velocities progressively decrease downstream from Léaz gorges to the dam. A downstream fining is observed with progressive deposition of the sediments in suspension depending on their settling velocity. On the contrary to clay and silt, sand is generally transported both in suspended load (graded) and bedload leading to more complex exchanges with the bed.

During flushing events, the progressive lowering of the reservoir water level allows to erode the bed material in the reaches where an accelerated flow is established. The reservoir draw down creates a flushing channel. The banks stability decreases and leads to their collapse. Then, when the reservoir is risen during the Swiss dams flushes, the sediment transport in the lower subreaches is related to the reservoir hydrodynamics. As a consequence, the second week of the flush is generally characterized by a large deposit of fine sediments coming from Swiss flushes, as shown in Fig. 4 downstream from the circles. The location of the extend of this deposit depends on the reservoir water level during the second phase of the flushing event.

No significant change of the grain size distribution of the river bed along-stream the reservoir has been observed through the last $15 \mathrm{yr}$. Since there is obviously some transport of coarse sediments, this may be explained by deposits of fine sediments over the coarser layers. Some two meter deep cores close to the dam confirmed the occurrence of alternate layers of clay, silts and sands (Bouchard and Dumond, 2000). 


\subsection{Dynamics of the reservoir during interflush periods}

At the Génissiat dam, only the water intakes for the provision of hydropower plants are operated during interflush periods. Those intakes are located at the upper third of the water level close to the dam. Thus, as flow velocities are also quite low, the sediment output is usually very low. Hydrological conditions that may be significant for sediment transport have been reported in Table 1 for the Arve River at Geneva and the Rhône River at Pougny. Indeed, a flood on the Arve River may provide a significant sediment supply to the Upper Rhône River and lead to deposition in Verbois, Chancy-Pougny and Génissiat reservoirs. A flood on the Upper Rhône River may erode sediments in the three reservoirs, but the Génissiat DAM management mitigates the sediment transport in the Génissiat reservoir. If dredged volumes are taken into account in the Génissiat reservoir sediment budget, we can notice that the two interflush periods with the highest deposited volume (1984-1987 and 1990-1993) are characterized by several floods on the Arve River and no significant event in the Rhône River.

\subsection{Dynamics of the reservoir during flushes}

A specific reservoir management procedure is operated during flushing events. Before the 1997 flush, a small part of the Génissiat reservoir bed material was eroded before the released sediments from Swiss dams flushes got into the reservoir and were partly deposited. Those patterns can be observed on Fig. 4 for 1984 to 1993 flushes. The middle subreaches of the reservoir encountered no significant evolution during this period. The downstream third of the reservoir is characterized by large sediment deposits released from Swiss reservoirs that occurred at the end of the flush.

Since 1997, the first phase of the flush allowed to erode the reservoir bottom from Léaz gorges to the dam. During the second phase, the efficiency of the transfer of fine sediments downstream Génissiat dam is closely related to the dam management. Different scenarios occurred between 1997 and 2012 (Fig. 4). During the 1997 and 2003 flushes, the reservoir was operated with the planed water level during the second phase and incoming sediment where mainly released downstream, with deposition only close to the dam, as highlighted by the circles on Fig. 4. During the second phase of the 2000 and 2012 flushes, the reservoir water level was higher due to unfavourable hydrological conditions and led to a significant deposition of the incoming material, beginning from Léaz gorges.

\section{Conclusions and perspectives}

A methodology was implemented to calculate the sediment volume budget in a reservoir based on bathymetric data described by cross sections. An estimation of uncertainties for those volumes was proposed. This methodology was used for
16 bathymetric campaigns to estimate sediment budgets of the Génissiat reservoir during flushes and interflush periods from 1984 to 2012. The spatial budget has allowed to divide the reservoir into four subreaches with homogeneous patterns. Further analysis of the budget combined to hydrosedimentary data has highlighted the mechanisms of sediment transport in the reservoir: bedload may prevail in the upstream part while suspended load of sand, silt and mud prevail in the downstream part. The morphological evolution of the reservoir during flush and interflush periods has been related to the reservoir management and sediment input.

In order to better understand local aspects and driving processes of the reservoir dynamics, an analysis based on the reservoir hydro-sedimentary parameters is needed. 1-D hydro-sedimentary models will be applied to reproduce both fine and coarse sediments dynamics, during flushing events and for long term periods. Moreover, some significant efforts should be made to get a better estimate of the incoming sediment fluxes in the reservoir using a turbidimeter and a hydrophone installed at Pougny.

Acknowledgements. Authors want to thank all technicians from Irstea and CNR for collecting the data.

\section{References}

Bouchard, J. and Dumond, L.: Exploitation of the results of the coring campain in Génissiat dam reservoir, Barrage de Génissiat: Exploitation des résultats de la campagne de carottages, Tech. rep., EDF, 2000 (in French).

Brandt, S.: A review of reservoir desiltation, Int. J. Sediment Res., $15,321-342,2000$.

Di Silvio, G.: Basic classification of reservoir according to relevant sedimentation processes, in: 29th IAHR World Congress, Bejing, China, 285-293, 2001.

Geay, T.: Passive hydrophone monitoring of bedload transport in gravel bed rivers [Mesure hydrophone du transport solide par charriage dans les rivières], $\mathrm{PhD}$ thesis, Joseph Fourier University, Grenoble, France, (in French), 2013.

Joint Committee For Guides in Metrology: Evaluation of measurement data - Guide to the expression of uncertainty in measurement, Tech. rep., BIPM, 2008.

Lerch, C. and Thizy, R.: 2012 flush sediments analysis, Analyses des sédiments: Chasse 2012, Tech. rep., CNR, 2013 (in French).

Morris, G. and Fan, J.: Reservoir Sedimentation Handbook: Design and Management of Dams, Reservoirs and Watersheds for Sustainable Use., McGraw-Hill, 1998.

Peteuil, C., Fruchart, F., Abadie, F., Reynaud, S., Camenen, B., and Guertault, L.: Sustainable management of sediment fluxes in reservoir by environmental friendly flushing: the case study of the Génissiat dam on the Upper Rhône River (France), in: ISRS Kyoto, Japan, (CDRom), 1147-1156, 2013. 